\title{
Rumores e condutas coletivas na pandemia: a teoria do complô sobre a origem da COVID-19
}

\author{
Rumors and collective conducts in the pandemic: the complot theory about the origin of COVID-19
}

\author{
Aparecido Francisco dos Reis ${ }^{6}$ \\ Faculdade de Ciências Humanas/Instituto de Saúde Integrada, Universidade Federal de Mato Grosso do Sul, Campo Grande, Mato \\ Grosso do Sul, Brasil. Autor para correspondência. E-mail: aparecido.reis@ufms.br
}

\begin{abstract}
Resumo: A pandemia atual gera incertezas em toda população, levando as pessoas a procurar explicações satisfatórias que poderão dar ordem e significado às suas experiências vitais. Atualmente, o coronavírus se tornou o inimigo mais recente. Mas as incertezas significativas persistem e nessa busca por respostas as pessoas criam teorias da conspiração, aquelas que apontam conluios entre poderosos como causa de problemas mais importantes. No texto a seguir, se discute o surgimento da pandemia e as teorias do conspiratórias acerca da origem SARS-CoV-2, causador da Covid-19. A metodologia usada foi a pesquisa de difusão de informações publicadas em comunidades virtuais do Facebook, que apontou na direção do reforço de crenças e condutas coletivas de apoio às teses conspiracionistas, principalmente aquelas que responsabilizam a China, o Partido Comunista Chinês e Bill Gates num conluio para dominação do mundo e da redução da população. A análise do material coletado contou com modestas incursões teóricas no campo da psicologia social e da sociologia.
\end{abstract}

Palavras-chave: saúde pública, rede social, conspiração.

\begin{abstract}
The current pandemic generates uncertainties in all the population, leading people to look for satisfactory explanations that may give order and meaning to their vital experiences. Presently, coronavirus has become the most recent enemy. However, all the meaningful ambiguities persist and in this search for answers people create conspiracy theories, those who point collusion among the powerful as cause of more important issues. In the following text, it is discussed the rise of the pandemic and the conspiracy theories concerning the origin of SARS-CoV-2 agent of Covid-19. The methodology adopted was the search of diffusion of information published on virtual communities of Facebook, which pointed the direction of reinforcement of beliefs and collective conducts for support to conspiracist theses, mainly those that make responsible China, The Chinese Communist Party, and Bill Gates in a collusion for the domination of the world and the reduction of the population. The analysis of the material gathered counted on modest theoretical incursions in the field of social psychology and sociology.
\end{abstract}

Keywords: public health, social network, conspiracy.

\section{Introdução}

A pandemia de COVID-19 perturba dramática e radicalmente o desempenho de nossas sociedades em todo o mundo. O alto potencial de contágio do SARS-CoV-2, causador da Covid-19, tem conspirado junto com os padrões de movimentos típicos da época atual, cada vez mais vigorosos, para propagar o vírus até os cantos mais remotos do planeta, sem respeitar classes sociais, condição econômica e ancestralidade. O número de casos ativos cresceu exponencialmente durante semanas na maioria das nações, saturando as capacidades dos sistemas de saúde em quase todas as latitudes. Forçados pelo rápido aumento do número de casos, os governos tiveram que tomar medidas extremas de distanciamento social e confinamento para conter a propagação do vírus.

Essas medidas estão tendo um impacto decisivo no imaginário social. Na era da internet, o cidadão comum se sente preso ao turbilhão de cifras, dados e notícias, às vezes contraditórias, que encontra no mundo virtual. Muitas pessoas podem passar mais tempo em casa procurando respostas on-line para uma situação incerta e em rápida mudança.

Por outro lado, no ecossistema de informação do mundo virtual, a notícia tem que competir por um escasso recurso que nós, humanos, fornecemos: nossa atenção. Uma espécie de preceito darwiniano dita que sobrevivam as mensagens mais atraentes, o que torna a publicação de notícias uma alquimia nas quais, as verdades frequentemente se fundem com as falsidades, realidade envolta no claro-escuro da subjetividade. 
Nesse estado de coisas, é fácil encontrar informações consistentes com o sistema de crenças de diferentes grupos sociais, que se sedimentam nos preconceitos e valores amplamente difundidos e aceitos num mundo profundamente marcado por extremos políticos e pela desconfiança no sistema mundial atual. Instituições sociais multilaterais como Organização Mundial da Saúde (OMS) e grandes fundações de apoio humanitário tem sido vistas sob o crivo da crítica no contexto do vírus globalizado, são acusados por movimentos conservadores de criarem o pânico na população, assim de terem se aliado à China na implantação de um projeto global de controle da população e do comunismo por meio da criação de um vírus de laboratório, aventando assim, a existência de uma trama internacional contra o mundo ocidental.

Isso tem ocorrido apesar da China ter sido o primeiro país detectar o vírus e informar a OMS e demais países em 31 de dezembro de 2019, dos casos surgidos em seu território. Além disso, a China tem mantido desde o início, um quadro controlado de contágio e de mortes. Nada disso não foi suficiente para eliminar as suspeitas de que o vírus possa ser uma estratégia da China e do Partido Comunista na guerra comercial com os Estados Unidos e com o restante do Ocidente.

No imaginário coletivo, representado por comunidades virtuais no Facebook e outras redes sociais, identificados como movimentos políticos de direita, defensores do presidente brasileiro Jair Bolsonaro e do presidente norte-americano Donald Trump, tem se difundido sem qualquer receio, teorias da conspiração que afirmam a tese do complô entre a China, OMS, corporações empresariais do ramo das comunicações e a Fundação Bill e Melinda Gates para o controle populacional e a dominação do mundo pelo comunismo.

\section{Materiais e métodos}

A proposta metodológica escolhida considera que os meios de experienciar a realidade são atualmente, profundamente afetados pelas redes sociais e a tecnologia, alterando o modo como as sociedades compreendem o mundo e os acontecimentos. Se em outras épocas, a tecnologia era apenas um instrumento hoje ela é uma forma de interpretação do mundo que se transforma em realidade. Nesse contexto, “uma das formas mais crescentes de comunicação virtual é a baseada nas redes sociais. Essas redes, indubitavelmente, são elementos não apenas de contatos sociais, mas, sobretudo, se constituem em eficientes instrumentos de propagação de ideologias, culturas e identidades" (Castro \& Spinola, 2015).

O Facebook, enquanto rede social hospeda diferentes páginas de comunidades de interesses ou assuntos variados, reunindo algumas delas, milhões de pessoas, que curtem, compartilham e comentam as postagens que lhes interessam. Ellison, Steinfeld e Lampe (2007) analisaram esta rede social na Internet enquanto suporte das relações sociais. Para os autores, os processos sociais foram modificados e permitiram o resgate de contatos e laços sociais que não existiam mais devido à distância. Este estudo mostra que a ferramenta possibilita aos atores a manutenção de uma rede social com a qual ele não teria mais contato. As comunidades hospedadas nessa rede além de publicizar as conexões ideológicas entre os participantes e seguidores, permitem que as concepções e formas de interpretação de fatos relevantes, como a pandemia de Covid-19 sejam expostas sem reservas.

Assim, o trabalho empregado neste ensaio foi acompanhar as postagens realizadas em três (3) comunidades de perfis conservadores no Facebook (facebook.com) durante todo mês de abril de 2020, são elas: Movimento Avança Brasil (https://www.facebook.com/MAvancaBrasil), com mais de 2 milhões de seguidores, definida em sua página de entrada como um movimento conservador; Movimento Pesquisar é Viver (https://www.facebook.com/Movimento-Pesquisar-\%C3\%89-Viver--463639647386051), definido como uma comunidade na qual se discute todos temas relacionados à ciência e a tecnologia, com pouco mais de 380 seguidores; Movimento Brasil de Direita (https://www.facebook.com/groups/285150341898012/). Esse movimento se define como "Grupo de direita que visa desmascarar as falácias propagadas pela esquerda nefasta que tenta transformar nosso país numa ditadura do proletariado, escravizando o povo e igualando-nos pela miséria". Tem mais de 20 mil membros. Essas comunidades divulgam sempre vídeos e textos relacionados a política e a defesa de valores considerados como conservadores e liberais como elas mesmos definem. Observa-se que todas elas procuram trazer notícias que fazem a defesa do governo de Jair Bolsonaro, vídeos de youtubers conservadores, políticos, pastores e religiosos (as) em geral. O vídeos e textos publicados no período analisado fazem referências aos mais diversos assuntos como se verá mais adiante, no entanto tem chamado muito atenção a postagem de materiais acerca da pandemia de Covid-19, que vão desde as narrativas 
acerca da origem do vírus, até as insistentes reportagens sobre as medições eficazes contra o coronavírus, principalmente, aquelas que recomendam o uso da hidroxcloroquina e cloroquina $\mathrm{O}$ acesso às publicações nas páginas das comunidades é livre para qualquer usuário que tenha uma conta Facebook.

$\mathrm{Na}$ análise do material houve o cuidado da checagem do que é publicado nas comunidades. Boa parte das notícias foram consideradas como falsas pelos sites Agência Lupa, Fato ou Fake, Pública, E-Farsas e Fake Check. Embora possam existir materiais publicados sobre fatos verdadeiros, neste texto, serão apenas discutidos as notícias ou rumores sobre a origem do vírus SARS-CoV-2. A escolha dessas notícias consideradas falsas se deu em razão da força que o imaginário sobre a teoria da conspiração possui, colocando do mesmo lado comunismo, China e poderosas corporações capitalistas. Essa trama ganha sentido quando milhares de seguidores, como pode se observar nessas comunidades, compartilham, comentam e de certo modo, procuram identificar o comunismo como o inimigo comum a ser combatido no Ocidente, como parte de uma guerra cultural que cria tensões e dúvidas sobre as intenções de organizações como a OMS, corporações e atores sociais significativos tem preocupações com a coletividade. Seguindo essa lógica, é possível perceber que a China poderia sim, criar um vírus intencionalmente e dispersa-lo no mundo todo, afinal, o comunismo pode fazer alianças com corporações empresariais, organizações multilaterais, políticos e até com estados nacionais, pois sempre teve como projeto dominar o mundo e estabelecer a ditadura do proletariado e a China aparece como suspeita por dois motivos principais: 1) o comunismo ou que se chama vulgarmente de marxismo cultural, e; 2) interesses comerciais.

Assim, busca-se identificar e analisar as publicações acerca da origem do coronavírus e as condutas coletivas de incertezas e de respostas ao surgimento da pandemia, por meio das teorias conspiratórias que colocam a China, o comunismo e outros agentes sociais e políticos como responsáveis pela criação e disseminação do SARS-CoV-2.

\section{Resultados e discussão}

A nível internacional, existem procedimentos e lineamentos acordados por vários países para orientar ações acerca de certos tipos de enfermidades e eventos de saúde pública, sendo o mais importante o Regulamento Sanitário Internacional (RSI) (OMS, 2005), um instrumento jurídico internacional de caráter vinculante para 194 países que tem por objetivo ajudar a comunidade internacional a prevenir e enfrentar as ameaças à saúde de suas populações suscetíveis de atravessar fronteiras e colocar em risco a saúde de todo o mundo. O RSI serve de marco jurídico para a prevenção, detecção e contenção na origem dos riscos para a saúde pública, antes que qualquer enfermidade se propague através das fronteiras , mediante a ação conjunta dos Estados membros da OMS, pois, obriga os governos a "notificar todos os eventos que que podem constituir uma emergência de saúde pública de importância internacional” (OMS, 2005) e estabelece definições amplas sobre o que constitui um "evento", "enfermidade" e "risco para a saúde pública" (OMS, 2005).

No caso do coronavírus Covid-19, desde 30 de janeiro de 2020 o Comitê de Emergências do RSI determinou que este representa uma emergência de saúde de importância internacional. Emitiu uma série de recomendações para a OMS, para a China e para o resto dos países, sugerindo a adoção de medidas de contenção como: vigilância ativa, detenção temporária, isolamento, controle dos casos, seguidos de contato e prevenção da propagação pública do coronavírus.

Embora o Comitê não tenha recomendado a imposição de restrição de viagens ou de comércio, assinalou que os países são obrigados a enviar a OMS em nome da saúde pública, como estão aplicando as medidas para que possam ser avaliadas sua viabilidade. O Diretor Geral da OMS, Tedros Ghebreyesus, manifestou sua preocupação por causa do nível de propagação do vírus, salientando que esta é a primeira em que se pode controlar, se todos os países agirem rapidamente com medidas agressivas para detectar, testar, tratar, isolar, rastrear e mobilizar a população para uma resposta controlada. Desta maneira, os países com poucos casos podem evitar que os mesmos se convertam em grupos e em transmissão comunitária. Mais ainda, aqueles países com transmissão comunitária podem mudar o rumo da epidemia, suprimindo e controlando o vírus como foi o caso da Alemanha e Coréia do Sul. No entanto, desde o início, a OMS reconheceu que alguns estavam lutando contra a pandemia, mas com falta de capacidade, insumos e recursos humanos, já outros simplesmente ignoraram a pandemia e não tomaram uma resolução de imposição de medidas imediatamente, caso dos Estados Unidos e do Brasil.

É preciso pensar que em muitas catástrofes e situações de risco se exige de governos e da população condutas adequadas, que permitam elaborar estratégias de combate à propagação do perigo e suas ameaças e

https://dx.doi.org/10.31533/pubsaude4.a0493 
dar tempo com o objetivo de organizar racionalmente os recursos humanos, técnicos e materiais necessários para enfrentar a situação de contingenciamento. Entretanto, em outras circunstâncias se observam condutas inadequadas como considerar que a situação de perigo é irreal ou fantasiosa, tendo como consequência, o aumento das fissuras e da desorganização social do grupo, assim como a exposição ao perigo (Ovejeiro, 1997)

O comportamento coletivo, imediato, mais frequente ante a uma catástrofe é a reação de comoção inibição - estupor, em curso do qual se vê os sobreviventes a emergir dos escombros, alterados pelo choque emocional, sem iniciativas e cuja única mobilidade é um lento êxodo centrífugo que os leva dos lugares da catástrofe para ganhar espaços mais amplos na periferia ou a lugares mais afastados do centro do desastre. Exemplos disso foram a destruição de Pompeia, os terremotos de Lisboa e do México e os bombardeios de Hamburgo, Tóquio, Hiroshima e Nagasaki durante a $2^{\text {a }}$ Guerra Mundial (Guillain, 1979; Pellegrino, 2010). Os testemunhos desses fatos descrevem longas e lentas filas silenciosas de sobreviventes, seguindo-se um após outro por caminhos improvisados entre a ruínas. Essas reações duram, em sua maior parte, algumas horas segundo Crocq, Doutheau e Sailhan (1987).

No caso da saúde pública, as investigações históricas sugerem que as epidemias de Peste e Cólera provocaram cenas de pânico, de medo intenso e dúvida coletiva, ostracismo, isolamento e abandono dos enfermos, inclusive de familiares e pessoas próximas, condutas de ataques a enfermos e a grupos considerados responsáveis pela epidemia (estrangeiros, judeus, médicos, entre outros). As condutas coletivas de pânico, dúvida, abandono de enfermos foi reproduzido parcialmente em episódios recentes de Aids na década de oitenta do século passado, no caso do ebola (Páez et al.,1991; Rushing, 1995; Páez, Marques, \& Beristain, 1998). Ainda que haja fortes diferenças entre a Europa do século XIV (Época da Peste) e de outros episódios mais recentes de epidemias, as reações são sempre similares. Assim, frente aos fatos traumáticos a necessidade de explicar o ocorrido e de encontrar um responsável é um fenômeno frequente, tanto em catástrofes sociais como em guerras ou epidemias.

Uma diferença importante foi que no século XIV se acusou os judeus de serem culpados pela epidemia de Peste, no século XIX, os ricos, as autoridades e os médicos acusaram os pobres de serem responsáveis pela epidemia de cólera. Os pobres acusaram os ricos, as autoridades e aos médicos pela doença, tendo como uma conduta comum, as agressões aos profissionais de saúde. Mas, a atribuição à enfermidade a estrangeiros também foi frequente. Os russos atribuíram a enfermidade aos poloneses; os poloneses culparam os russos e os europeus ocidentais responsabilizaram poloneses e russos. Os pobres e o imigrantes, como os irlandeses nos Estados Unidos, também foram bodes expiatórios durante a doença (Delumeau, 1993).

Entretanto, nem todas a epidemias mortais provocam o mesmo impacto. Por exemplo a epidemia de influenza ocorrida neste século, não produziu condutas de pânicos ou violência. Estes tipos de condutas são mais comuns quando: a) a enfermidade é fortemente letal; b) aparece de repente; c) a taxa de mortalidade aumenta rapidamente; d) se acredita que que muitas pessoas estão em risco de contrair a enfermidade; e, e) a causa da enfermidade é desconhecida. Na epidemia de influenza se conhecia a causa, teve um conjunto de medidas preventivas e controle sanitário bem delineados como o uso de máscaras, limpeza de ruas e das mãos com álcool em gel, etc. Ainda que estas não fossem efetivas, a sensação de controle diminui o medo ao contágio (Rushing, 1995). As epidemias de Cólera e Peste produziram pânico e medo coletivo em razão do fracasso das crenças sociais existentes para explicar o que se passava.

Outro problema a ser abordado são os rumores que proliferam ao longo de qualquer catástrofe, tragédia e pandemias e podem minar o funcionamento de uma sociedade. Uma boa forma de enfrentá-los é facilitar a veiculação de informações críveis e adequadas tanto quanto seja possível. A informação deve incluir todos os fatos, as consequências, a evolução do quadro de ocorrências e como a sociedade deve seguir, em caso de uma pandemia, as medidas sanitárias recomendadas. As informações devem ser precisas, pois sempre existe o risco de compartilhamento de notícias que podem colocar em perigo os membros da sociedade. Na época atual, é importante destacar que as notícias que ameaçam a eficácia de medidas sanitárias acerca da pandemia de Covid-19, tem circulado muito rapidamente em redes sociais como Facebook e outras, sobretudo nos grupos que reúnem pessoas com identidades político-ideológicas comuns.

A OMS informou que o vírus teve seu início na província de Wuhan, na China. Inicialmente, se cogitou que o vírus tenha sido adquirido por chineses que comem costumeiramente carne de cobra e de pangolim, mas, após avaliação, a OMS afirmou que isso seria improvável e sugeriu que o problema se iniciou após a ingestão de uma sopa feita com carne de morcego ( https://www.paho.org/bra). Ou será que não? Isso criou dúvidas acerca da narrativa tanto da China quanto da OMS em relação à pandemia. As dúvidas e as incertezas em relação à origem do vírus causador da Covid-19, tem criado diferentes condutas de reação de parte da 
população em relação a pandemia, fomentando narrativas para a origem do vírus, para o processo de infecção, para as formas de tratamento, cura e para o número de mortes provocados pela Covid-19.

Além disso, autoridades brasileiras, influentes nas comunidades pesquisadas como o presidente Jair Bolsonaro em 16/03/2020, falou que a pandemia é parte de um plano de recuperação econômica do governo chinês. Essa ideia bastante explorada na internet foi compartilhada pelo presidente e por seus filhos. Bolsonaro entende "que toda vez que a China tem problemas econômicos, uma grande doença aparece para causar crise nos mercados globais e diminuir os produtos que são importados do Brasil”. O presidente lembra dos casos das gripes aviária e suína como exemplos de outras pandemias parecidas. Segundo o governante brasileiro, a "China já está comprando petróleo 30\% mais barato do que antes do aparecimento da doença, além de pagar menos por commodities exportadas do Brasil, como minério de ferro". (https://istoe.com.br/bolsonaroassocia-pandemia-de-novo-coronavirus-a-plano-de-governo-chines-diz-colunista)

A narrativa é reforçada pelo deputado federal Eduardo Bolsonaro, filho do presidente, retuitou postagem de Rodrigo da Silva, fundador do portal Spotniks, responsabilizando governo chinês pela pandemia do coronavírus. "A culpa é da China e liberdade seria a solução", afirmou. A postagem de Eduardo Bolsonaro foi amplamente reproduzida nas três comunidades pesquisadas.

O ministro das Relações Exteriores do governo Bolsonaro, Ernesto Araújo em um texto intitulado "Chegou o Comunavírus" publicado no dia 21/04/2020 em seu blog Metapolítica 17 (https://www.metapoliticabrasil.com/) e reproduzido na comunidade Movimento Avança Brasil, comenta o livro "Vírus" de Slavoj Zizek. No texto, Ernesto Araújo afirma que a pandemia faz parte de um "projeto globalista que é o novo caminho do comunismo". O ministro entende que tal projeto "já se vinha executando por meio do climatismo ou alarmismo climático, da ideologia de gênero, do dogmatismo do politicamente correto, do imigracionismo, do racialismo ou reorganização da sociedade pelo princípio da raça, do antinacionalismo, do cientificismo.

Para o diplomata, tais elementos são instrumentos eficientes de dominação, que adicionados a pandemia, coloca indivíduos e sociedades diante do pânico da morte iminente, representa a exponencialização de todos eles.

Araújo fala de suas ideias questionando entidades internacionais como a Organização Mundial da Saúde (OMS). Para o ministro, "transferir poderes" à entidade multilateral esperando que ela seja mais "eficiente para lidar com os problemas do que os países agindo individualmente é um pretexto jamais comprovado". Ele pensa que isso representa a deflagração do projeto de construção da sociedade comunista no planeta inteiro.

A fala de autoridades brasileiras ligadas ao governo Bolsonaro contrariando recomendações da OMS e de cientistas e especialistas em saúde pública, se reflete em parcelas da população que estão conectadas às páginas das comunidades conservadoras do Facebook, agudizando ainda mais a desconfiança sobre a pandemia ao fornecer elementos para formação e sustentação de uma teoria da conspiração entre a China, a OMS e demais organizações e corporações.

$\mathrm{Na}$ análise realizada nas três (3) comunidades escolhidas, essas e outras notícias ou rumores sobre a Covid-19, mesmo aquelas que foram desmentidas por sites de checagem ou pela imprensa convencional, foram e continuam sendo amplamente difundidas. Durante o mês de abril de 2020, houve postagem de sessenta e duas (62) diferentes notícias consideradas falsas (fake news) sobre a Covid-19, tratando dos seguintes assuntos descritos no quadro abaixo.

Entre os mais variados rumores publicados no período, neste ensaio será abordado o rumor ou a notícia sobre a origem do vírus SARS-CoV-2, em razão de sua amplitude e aceitação nas comunidades pesquisadas, pois foram difundidos em diferentes postagens, sendo que alguns deles, foram postados várias vezes. $\mathrm{O}$ aspecto mais importante dessas notícias é que elas vêm sendo difundidas desde o início da pandemia. A primeira dela diz respeito a tecnologia $5 \mathrm{G}$ utilizada em aparelhos de celulares.

Primeiramente, essa notícia ou rumor foi postada em vídeo do Youtube e depois disseminado nas comunidades em questão, sendo republicado por mais de uma vez. Ao que parece foi publicado inicialmente em um grupo de conspiracionistas anti-5G na Holanda logo no início da pandemia, criado no Facebook pelo pesquisador de OVNIs John Kuhless. No comentário sobre o vídeo, ele diz: “Eu desafio qualquer pessoa a assistir esse vídeo pelo menos duas vezes e dizer que não tem nada a ver, ou que é tudo uma coincidência. Ah, claro. Com certeza não".

Kuhless se refere a um vídeo publicado na mesma época, pela youtuber conspiracionista cristã Dana Ashlie, que conta com pouco mais de 200 mil inscritos em seu canal. No vídeo, Ashlie comenta sobre a disponibilização comercial do $5 \mathrm{G}$ em Wuhan e como isso teria sido responsável pelo início da Covid-19. Observando o seu canal, pode perceber que entre os conteúdos abordados, a youtuber acusa a cantora Taylor Swift de disseminar propaganda anticristã em suas músicas; e outro afirmando categoricamente que Nikolas Cruz, o atirador que matou 17 pessoas no tiroteio da escola colegial Marjory Stoneman Douglas na Flórida (EUA) em fevereiro de 2018, era na verdade a vítima de um "dispositivo militar secreto de controle remoto". 
Quadro 1. Assuntos publicados nas comunidades.

\begin{tabular}{|c|c|c|}
\hline Categoria & Conteúdo & Meios \\
\hline Vírus & $\begin{array}{l}\text { Origem do vírus( criado em laboratório pela China), transmitido pela } \\
\text { tecnologia } 5 \mathrm{G}\end{array}$ & $\begin{array}{l}\text { vídeos de Youtubers e } \\
\text { textos }\end{array}$ \\
\hline Medicamentos & $\begin{array}{l}\text { Hidroxicloroquina, ivermectina, gargarejo de vinagre com sal, anita, heparina e } \\
\text { outros }\end{array}$ & $\begin{array}{l}\text { vídeos e textos de } \\
\text { médicos } \\
\text { reportagens de TV, } \\
\text { vídeos de Jair Bolsonaro }\end{array}$ \\
\hline Hospitais & Denúncia de leitos vazios & vídeos \\
\hline Mortes & $\begin{array}{l}\text { Denúncias de enterros de caixões vazios, atestado de óbitos falsos, cemitérios } \\
\text { vazios, notificação falsa de covid-19, dengue mata mais, armamento }\end{array}$ & $\begin{array}{l}\text { link de sites, vídeos e } \\
\text { textos }\end{array}$ \\
\hline Isolamento & $\begin{array}{l}\text { Crítica aos governadores e prefeitos, isolamento vertical, carreatas, economia, } \\
\text { desemprego, fome, quebra do comércio, gripezinha, resfriado, mais curas do } \\
\text { que mortes. Rede Globo (Globolixo). Mídia esquerdista. }\end{array}$ & textos e vídeos \\
\hline Política & $\begin{array}{l}\text { Superfaturamento e corrupção na compra de equipamentos hospitalares, } \\
\text { comunismo chinês, China quer dominar o mundo, dependência da China. } \\
\text { Governadores comunistas. }\end{array}$ & vídeos e textos \\
\hline
\end{tabular}

As Agências de checagem, já aqui citadas, desmentem constantemente a youtuber, aliás: a maior parte dos difusores dessa ideia de que o $5 \mathrm{G}$ é responsável pela disseminação do Covid-19 se atém à ideia de que Wuhan foi o primeiro local a disponibilizar esse tipo de conexão. Embora isso seja parcialmente verdadeiro, Segundo o site do Yahoo Notícias (https://br.financas.yahoo.com/noticias), a conexão existe apenas em parques e praças públicas, mas a localidade não foi a primeira região da China a contar com esse tipo de tecnologia. As afirmações de que o $5 \mathrm{G}$ de afeta de alguma forma o sistema imunológico humano também não encontram qualquer respaldo científico, mas isso, de modo algum, impede que os conspiracionistas afirmem que a radiação emitida pelo $5 \mathrm{G}$ - o termo radiação é bastante utilizado nas comunidades pesquisadas - é que produz esse efeito na imunidade humana. (https://br.financas.yahoo.com/noticias)

Outras versões dessa conspiração a tornam ainda com mais elementos imaginativos: um post na Comunidade Avança Brasil fala sobre a "maléfica" combinação entre o " $5 \mathrm{G}$, poeira inteligente, vacinas e ativação remota” do Covid-19 nas pessoas. Como prova do que estão postando, descrevem episódios sobre o assunto. Um destes episódios, se refere ao navio de cruzeiro Diamond Princess, que ficou em quarentena no mar, próximo ao porto de Yokohama (Japão), após passageiros infectados serem identificados a bordo. Segundo essa narrativa, esse episódio revela claramente um caso de ativação remota do coronavírus, já que a embarcação seria "especificamente equipada com uma antena $5 \mathrm{G}$ de $60 \mathrm{GHz}$ ". A narrativa é mantida como verdadeira, apesar da empresa Princess Cruises, proprietária navio em questão ter informado que não há nenhuma atena $5 \mathrm{G}$ instalada a bordo.

A postagem finaliza dizendo que o presidente norte-americano Donald Trump "criou uma força especial" para "combater essa tecnologia armada", antes de sugerir aos seus eleitores que se recusem a tomar vacinas obrigatórias "porque nossas vidas dependem disso".

As narrativas conspiracionistas se intensificam a ponto de dar origem a especulações sobre um laboratório em Wuhan que teria, talvez por acidente ou de forma intencional, causado uma das piores pandemias globais da história. Amplamente difundidos nas comunidades pesquisadas, esses rumores foram reforçados com a publicação de uma investigação do Washington Post em 14 de abril de 2020 (https://www.washingtonpost.com) e de uma reportagem da Rede de Televisão Fox News no dia 15 do mesmo mês. Tanto o Washington Post quanto a Fox são conhecidos por suas posições conservadoras.

Os referidos meios de comunicação levantaram a hipótese do vírus ter vazado do laboratório de Wuhan por causa do uso de protocolos de segurança mal formulados. O desconhecido "paciente zero" do Covid-19 poderia ser, ainda segundo a Fox News "um funcionário do laboratório que teria sido acidentalmente contaminado".

Tais informações são ainda corroboradas pelo diplomata americano Mike Pompeu. Quando questionado no canal da Fox News, afirma que o governo americano abriu uma investigação sobre a origem do Covid-19. 
"Estamos realizando uma investigação completa sobre tudo o que podemos aprender sobre como esse vírus se espalhou, infectou o mundo e causou uma tragédia. Apenas o fato de termos que fazer essas perguntas, apenas o fato de não sabermos as respostas, de que a China não compartilhou as respostas, diz muito. O que sabemos é que esse vírus nasceu em Wuhan, na China. O que sabemos é que o Instituto de Virologia de Wuhan fica a poucos quilômetros do mercado de rua e ainda há muito a aprender".

Outro vídeo fala do presidente dos Estados Unidos, Donald Trump. Este considera o assunto da origem do vírus como estratégico no embate entre a China e os Estados Unidos no campo político e comercial. "Posso dizer que estamos ouvindo cada vez mais essa história. Vamos ver", disse o presidente de forma evasiva, mas sua fala lança controvérsias que divide a opinião pública e move seus seguidores.

Ainda sobre a origem do vírus, a tese, até agora defendida por especialistas e pela OMS, explica que esse vírus presente nos morcegos teria sofrido uma mutação para ser transmitido a uma outra espécie animal. Esta espécie animal, ainda não confirmada pode ser o pangolim que a teria então transmitido aos humanos. Desde então, as autoridades chinesas falam de um mercado ao ar livre em Wuhan, onde são vendidos animais silvestres vivos. É neste mercado que se diz que o misterioso "paciente zero" do Covid-19 teria sido infectado.

Uma outra postagem publicada nas comunidades Movimento Avança Brasil e Brasil de Direita, assegura que hackers teriam invadido no dia 22/04/2020, os computadores da Fundação Bill e Melinda Gates, da OMS e do Instituto de Virologia de Wuhan e teriam vazado milhares de documentos e e-mails que indicariam que o coronavírus teria sido intencionalmente criado no laboratório de Wuhan, com componentes associados ao HIV (vírus da aids) e com participação da referida fundação. A informação foi inicialmente postada pelo empresário Mike Coudrey, nos Estados Unidos. Em sua fala num vídeo legendado em português, reitera a teoria de que o patógeno foi fabricado artificialmente.

Membros das comunidades pesquisadas reproduziram essa teoria que mostravam um vídeo de uma conferência de 2015 ministrada por Gates no "Event 201", na qual ele discute o surto de Ebola e alertou para as possibilidades uma nova pandemia - para reforçar as alegações de que ele tinha conhecimento prévio da pandemia de covid-19 ou mesmo que tenha causado isso de propósito. A ideia básica dessa teoria se sustenta na hipótese de que a covid-19 faz parte de uma trama internacional liderada por Bill Gates para vacinar a população mundial. Os ativistas de direita espalharam a narrativa de que Gates quer usar um programa de vacinação em escala global para implantar microchips digitais com a finalidade de rastrear e controlar população.

As postagens analisadas obtiveram milhares de comentários e compartilhamentos dos membros das comunidades virtuais pesquisadas, nesse sentido, serão reproduzidos comentários que corroboram com a tese da teoria da conspiração

Comentadora 1: Esse vírus foi planejado metodicamente pela China pra ser implantado a nova ordem mundial do comunismo.

Comentadora 2: Guerra fria,química para reduzir população a começar por idosos,acabar de vez com micros e pequenos empresários. Misturar pandemia com política deu ruim.

Comentadora 4: Mas o Brasil é mais fico, por isso a China e os comunistas querem tanto nosso país.

Comentadora 5: A única pandemia é a corrupção ... a doença em si, não mata. mais este parlamento brasileiro sim.

Comentadora 6: Gente isso é um jogo político quanto mais gente morrer melhor é para os governadores eles estão escondendo os medicamentos que eu vi em uma publicação então eles quer que os fraco morre só vai sobreviver os forte coisa do anticristo Isso é uma preparação do anticristo eliminar a terça parte do povo do mundo

Comentador7: E mais pensa comigo, a china está vendendo equipamentos superfaturados, respirador de 60 mil a passou a custar 600 mil reais, ai você acha que eles estão preocupados com a saúde do mundo? Ou com a economia dos próprios?, china sofre sansão de EUA e também da Rússia, pois ambos tem a suspeita dos chineses, outra situação o governo chinês sábia da gravidade do virús uns 7 dias antes, mas resolveu se calar, ai eu te pergunto qual foi a intenção deles? Já se sabe que o virus saiu de um pesquisador e não do mercado de wuhan como eles noticiaram, ai eu pergunto para você que já é um homem vivido, o que você faz para ver se um experimento seu dá certo? Testando pra ver o grau de eficácia.

Comentador 8: Máscaras devidamente contaminadas/infectadas pelo COVID-19, para acabar de phuder com os brasileiros. Afinal, esse país tem q ser despovoado o qto antes para os chineses tomarem de conta, simples assim.

https://dx.doi.org/10.31533/pubsaude4.a0497 
Comentador 9: A questão não é pela contaminação. Não tem esse risco! O problema é o Brasil dar dinheiro pra esses comunistas fdp. Por causa do partido comunista da China, esse vírus se espalhou. Todos países deviam boicotar a China.

Esses rumores são amplamente divulgados pelos seguidores da teoria da conspiração das referidas comunidades virtuais, revelam a crença numa teoria da trama entre governos e autoridades mundiais em saúde. Tais teorias não tem uma base científica, mas alimentam o imaginário social, sobretudo de seguidores de ideologias defensoras de Jair Bolsonaro e Donald Trump que veem a China, OMS e outros agentes como inimigos poderosos do Ocidente, da família e dos valores cristãos.

No entanto, estudos científicos descartam que o novo coronavírus seja uma arma biológica projetada e lançada intencionalmente ou por acidente. Em artigo publicado na Revista Nature Medicine, especialistas afirmam que "Although the evidence shows that SARSCoV-2 is not a purposefully manipulated virus, it is currently impossible to prove or disprove the other theories of its origin described here". (Andersen, Rambaut, Lipkin, \& Holmes, 2020). Isso quer dizer que os autores descrevem outras hipóteses para a explicação da transição do vírus de animais para os humanos, mas em nenhuma delas, consideram a possibilidade de uma teoria da conspiração para prejudicar ou aniquilar parte da humanidade.

Eventos naturais, sociais ou pandêmicos normalmente têm mais de uma causa e nessa tentativa de entender como ocorrem, surgem diferentes grupos de pessoas, apontando as causas biológicas e até políticas para pandemia. A discussão parece se enquadrar no contexto de situações de catástrofes em que narrativas conspiratórias percorrem o imaginário, frequentemente alimentado por fantasias sobre o inimigo, nesse caso, do comunismo, do poderio chinês e das corporações empresariais. Embora estas últimas façam parte do sistema capitalista, não deixam de suscitar suspeitas sobre seus interesses e ações, particularmente, os grupos de comunicação e as fundações filantrópicas ligadas a um empresário poderoso como Bill Gates.

Assim, em tempos como estes, proliferam explicações que podem ser identificadas como teorias da conspiração, do complô ou ainda teoria da trama. Nicolas (2016) propõem um esquema para explicar teoricamente como são pensados os termos complô, trama e conspiração. Para o autor, os termos designam:

“(a) uma ação acordada entre pelo menos duas pessoas, (b) preparada secretamente, em outros termos, escondida do olhar daqueles que não conspiram e, (c) buscando prejudicar, quer uma personagem pública ou uma instituição, quer, como geralmente é o caso nos dias de hoje, as maiorias, o povo, os cidadãos, as massas trabalhadoras, as pessoas honestas, etc. As manobras postas em questão (d) são suspeitas, então, de desestabilizar uma certa ordem de coisas que se considera harmoniosa, criar desordem ou uma ruptura na continuidade das coisas, colocar em perigo aquilo que, até então, se considerava bem estabelecido, seguro e estável" (Nicolas, 2016).

A partir disso, o autor compreende que, de uma forma ou de outra, situações que geram rupturas e "dramas como guerras, epidemias, pandemias e catástrofes" (Nicolas, 2016) podem ser interpretadas por parcelas da sociedade, como o resultado de um plano, de um acordo secreto ligado a uma certa intenção e acertos de organizações e homens que têm uma capacidade de prejudicar e um poder inversamente proporcional ao fato de serem poucos em número. Pode ser que as pessoas não tenham todos os detalhes da trama, mas reforçam a sua existência à medida que o acontecimento seja mais sentido como injusto e doloroso, difícil de aceitar, incompreensível diante das formas comuns de compreensão do mundo. Assim, "ele é suscetível de receber uma explicação do tipo conspiracionista, a qual se empenha, ainda que minimamente, para restaurar o sentido perdido e recolher os pedaços de uma experiência em frangalhos" (Nicolas, 2016). Essas teorias dão corpo e forma humana às causas de uma desgraça qualquer, ativam a imaginação e convidam a eternizar por meio dos testemunhos e das narrativas que o evento de fato, aconteceu.

A teoria da conspiração aparece em circunstâncias em que eventos socialmente importantes podem gerar incerteza suficiente em certas pessoas e as explicações convencionais não são satisfatórias. É importante esclarecer que a existência de ambições de poder e controle são comuns entre grupos humanos; ou seja, basta olhar para o ambiente próximo e reconhecer que as pessoas são capazes de conspirar para obter benefício pessoal ou para grupo do qual fazem parte, tendo condutas consideradas como imorais ou corruptas. Ao pensar nisso em cenários com maior poder, o impacto dessas conspirações tende a aumentar.

Outra característica associada a esse pensamento conspiratório "é a preferência por um processamento de informações mais intuitivo em vez de mais analítico" (Swami et al., 2014). Em outras palavras, pessoas que defendem conspirações são mais propensas a superestimar o conhecimento vindo da intuição em vez do 
conhecimento que surge através de um processo mais lento e mais metódico. Embora a intuição seja um processamento útil e eficiente em muitas ocasiões, sobretudo na vida prática, superestima-lo à custa de uma análise cuidadosa e detalhada pode-se cometer distorções significativas e tirar conclusões precipitadas, sem a devido contraste entre as opções para resolver um problema.

Por esse motivo, se um menu de opções aparecer antes de um evento de grande impacto social, pode oferecer explicações variadas, e às vezes complexas, no qual vários fatores vão estar inter-relacionados, o pensamento conspiratório provavelmente decide valorizar as informações que as pessoas "sentem" que estão corretas e, embora isso possa ser normal para todos, a diferença seria um baixo compromisso de querer reavaliar essa consideração à luz de um processo mais racional, mais analítico. E que consequências isso pode trazer? Pode levar grupos inteiros de pessoas a tomar decisões inadequadas, sendo menos responsáveis em suas condutas, rejeitando fontes especializadas e científicas. No caso da pandemia, há um sentimento hostil nas comunidades pesquisadas à OMS, à China, aos médicos que não receitam cloroquina, aos governadores que obrigam os médicos a emitir atestado de óbitos falsos e a outras organizações humanitárias, ligadas à saúde e aos direitos humanos.

Em geral, quando se acredita em conspirações no campo da saúde como nesse caso ou em outros, quando acredita-se que médicos escondem a cura da doença porque os poderosos o desejam, a confiança e a adesão ao aconselhamento médico diminuem, enquanto aumenta a confiança em fontes alternativas e não de saúde convencional (Oliver \& Wood, 2014).

\section{Conclusão}

Como se disse anteriormente, pretendeu-se no presente texto discutir as condutas coletivas com base nas teorias da conspiração a partir da análise das comunidades virtuais do Facebook. Isso pareceu relevante, pois apesar da literatura reunir informações sobre essas teorias e seu impacto na vida das pessoas e organizações sociais, pouco se tem estudado a respeito do fenômeno no contexto da pandemia de Covid-19, mesmo que se conheça a associação das crenças nessas teorias com comportamentos prejudiciais comuns na sociedade brasileira, como: problemas de saúde, posições ideológicas extremistas, hostilidades aos profissionais de saúde, invasão de hospitais, baixa adesão às recomendações sanitárias (isolamento social e uso de máscaras)

A profunda necessidade antropológica de manter controle sobre o meio social pode ajudar a explicar a razão de as teorias da conspiração ganharem impulso particularmente em contextos de eventos sociais impactantes que nestas situações, são experimentados como ameaças de controle por parte da população e de governos.

Destacam-se que as ideias conspiratórias tendem a reduzir a complexidade da realidade, de modo a explicar eventos políticos, sociais ou de saúde pública como se fossem organizados por indivíduos ou por confabulações secretas entre agentes políticos e econômicos com interesses comuns. Essas narrativas fazem com que os participantes dessas comunidades rejeitem argumentos baseados no conhecimento científico e adotem discursos alternativos para substituir evidências proporcionadas pela ciência, mas que estão de acordo com suas convicções. Desse modo, os grupos sociais que afirmam ser o coronavírus uma criação intencional da China e seus aliados, acreditam que esta é uma doença criada para contaminar a população mundial e controlar o comércio internacional. No mesmo sentido, se pode dizer, que a adoção de teorias conspiratórias decorre da ignorância e das dificuldades que os indivíduos têm de exercer um juízo crítico a partir de dados científicos.

Por fim, a conduta refratária do governo Bolsonaro à ciência, OMS e ao comunismo chinês converge para a crença de que as teorias conspiratórias envolvem organizações ou grupos que se unem com o objetivo de controlar e influenciar as informações fornecidas pela mídia, disseminar versões convenientes de acontecimentos de difícil explicação ou que favoreçam interpretações especulativas sobre a origem do vírus e da pandemia de Covid-19.

\section{Referências}

Andersen, K. G., Rambault, A., W., Limpkin, I., \& Holmes, E. C. 2020. The proximal origin of SARS-CoV-2, Nature Medicine, 17, 450-452.

Castro, F. M. M., \& Spinola, C. A. 2015. Metodologia de pesquisas na internet: breves considerações sobre uma pesquisa qualitativa em turismo nas redes sociais. Revista Iberoamericana de Turismo, 5(1), 170-188.

Crocq, L., Doutheau, C., \& Sailhan, M. 1987. Les réactions émotionnelles dans les catastrophes. Encyclopédie Médico Chirurgicale- Psychiatrie, 2-8.

https://dx.doi.org/10.31533/pubsaude4.a0499 
Delumeau, J. 1993. La peur en Occident. Paris, FR: Fayard.

Ellison, N., Steinfeld., \& Lampe, C. 2007. The Benefits of Facebook “Friends:” Social Capital and College Students' Use of Online Social Network Sites. Journal of Computer Mediated Communication, 12(4), 1143-1168.

Guillain, R. 1979. La guerre du Japon. Paris, FR: Stock.

Nicolas, L. 2016. As teorias da conspiração como espelho do século: entre a retórica, a sociologia e a história das ideias. Revista Eletrônica de Estudos Integrados em Discurso e Argumentação, 12, 255-279.

Oliver, J. E., \& Wood, T. J. 2014. Conspiracy Theories and the Paranoid Style(s) of Mass Opinion. American Journal de Political Science, 58(4), 952-966.

Ovejeiro, A. 1997. El individuo en la masa: psicología del comportamiento colectivo. Oviedo, ES: Nobel.

Páez, D., San Juan, C., Romo, I., \& Vergara, A. 1991. Sida: Imagen y prevención. Madrid, ES: Fundamentos.

Páez, D., Marques, J., \& Beristain, C. M. 1998. Conductas colectivas: rumores, catástrofes, pánicos y movimientos de masas. Psicología Social. Madrid, ES: McGraw-Hill.

Pellegrino, C. 2010. O último trem de Hiroshima: os sobreviventes olham para trás. São Paulo, SP: Leya.

Rushing, W. A. 1995. The AIDS Epidemic: Social dimensions of an infectious disease. Boulder, US: Westview Press. Organização Mundial da Saúde [OMS]. 2005. Regulamento Sanitário Internacional. 2005. Genebra, SW: OMS.

Swami, V., Voracek, M., Stieger, S., Tran, U. S., \& Furnham, A. 2014. Analyti c thinking reduces belief in conspiracy theories. Cognition, 133(3).572-585.

\section{Minicurrículo}

Aparecido Francisco dos Reis. Graduação em ciências sociais pela Universidade Estadual Paulista Julio de Mesquita Filho (1992), mestrado em ciências sociais (Sociologia Política) pela Universidade Federal de São Carlos (1997) doutorado em Serviço Social, Trabalho e Sociedade pela Universidade Estadual Paulista Julio de Mesquita Filho (2001) e Pós doc em Saúde Coletiva pela UNIFESP. Atualmente é professor associado IV na Universidade Federal de Mato Grosso do Sul. Tem experiência com orientações de PIBIC e mestrado, atuando na área de Sociologia, Antropologia com ênfase diversidade sexual e saúde coletiva, com aproximadamente 40 publicações entre livros e artigos em periódicos brasileiros e internacionais. Consultor de diversas revistas como: Bagoas (UFRN), Interações (UCDB), Multitemas (UCDB), Itinerários (Universidade de Varsóvia), Katalysis (UFSC), Em Tese (UFSC), membro do conselho editorial da revista E-legis do Programa de PósGraduação da Câmara dos Deputados. Membro do conselho editorial do periódico Humanities and Social Sciences da Universidade de Nova Dheli (Índia). Consultor da Fundect (Fundação de Amparo à Pesquisa de Mato Grosso do Sul) e da Fundação de Amparo à pesquisa do DF.

Como citar: Reis, A.F. 2020. Rumores e condutas coletivas na pandemia: a teoria do complô sobre a origem da COVID-19. Pubsaúde, 4, a049. DOI: https://dx.doi.org/10.31533/pubsaude4.a049

Recebido: 1 jul. 2020.

Revisado e aceito: 26 jul. 2020.

Conflito de interesse: os autores declaram, em relação aos produtos e companhias descritos nesse artigo, não ter interesses associativos, comerciais, de propriedade ou financeiros que representem conflito de interesse.

Licenciamento: Este artigo é publicado na modalidade Acesso Aberto sob a licença Creative Commons Atribuição 4.0 (CC-BY 4.0). 